\title{
KONTRUKSI DAN KARAKTERISTIK DISTRIBUSI INVERS WEIBULL DISKRIT BIVARIAT
}

\author{
Rizka Amalia $^{1, \text { a) }}$, Suyono ${ }^{2, \text { b) }}$, Fariani Hermin Indiyaha ${ }^{1, c)}$ \\ 1 Program Studi Matematika, Fakultas Matematika dan Ilmu Pengetahuan Alam, Universitas Negeri Jakarta \\ 2Program Studi Statistika, Fakultas Matematika dan Ilmu Pengetahuan Alam, Universitas Negeri Jakarta \\ Email: ${ }^{\text {a) }}$ rzkamaliaa8@gmail.com ${ }^{\text {b) }}$ suyono@unj.ac.id ${ }^{\text {c) }}$ farianihermin828@gmail.com
}

\begin{abstract}
This study reviews about construction and characteristics of bivariate discrete inverse weibull distribution. Bivariate discrete inverse weibull distribution was formed by defining $\mathrm{X}_{1}=\max \left(\mathrm{W}_{1}, \mathrm{~W}_{3}\right)$ and $\mathrm{X}_{2}=\max \left(\mathrm{W}_{2}, \mathrm{~W}_{3}\right)$, which is $\mathrm{W}_{1}, \mathrm{~W}_{2}$, and $\mathrm{W}_{3}$ are discrete inverse weibull distribution. Characteristics of bivariate discrete inverse weibull distribution discussed in this thesis are about mixed moment, covariance, and coefficient correlation. Numerical calculations using Octave program are presented in this study to show the performance of direct mixed moment.
\end{abstract}

Keywords: discrete inverse weibull distribution, mixed moment, covariance coefficient correlation.

\begin{abstract}
Abstrak
Penelitian ini membahas kembali mengenai kontruksi dan karakteristik dari distribusi Invers Weibull Diskrit bivariat. Distribusi Invers Weibull Diskrit bivariat dikonstruksi dengan mendefinisikan variabel acak $X_{1}=\max \left(W_{l}, W_{3}\right)$ dan $X_{2}=\max \left(W_{2}, W_{3}\right)$, dimana $W_{l}, W_{2}$, dan $W_{3}$ berdistribusi Invers Weibull Diskrit. Karakteristik distribusi Invers Weibull Diskrit bivariat yang dibahas adalah mixed moment, kovariansi, dan koefisien korelasi. Perhitungan numerik dengan menggunakan program Octave diberikan pada penelitian ini untuk menunjukkan kinerja langsung dari mixed moment.
\end{abstract}

Kata-kata kunci: distribusi invers weibull diskrit, mixed moment, kovariansi, koefisien korelasi.

\section{PENDAHULUAN}

Waktu hidup dari suatu komponen seringkali tidak dapat diprediksi secara pasti. Waktu hidup merupakan waktu sejak komponen mulai dioperasikan sampai komponen tersebut rusak atau gagal. Waktu hidup dari suatu komponen dapat dimodelkan dengan suatu variabel acak. Pada pemodelan waktu hidup perlu dipelajari distribusi dari variabel acak tersebut. Distribusi yang dapat digunakan untuk pemodelan waktu hidup dalam banyak bidang ilmu pengetahuan antara lain Gamma (Nelson, 
1982), Eksponensial, Weibull (Nelson, 1982; Bain, 1991) dan Invers Weibull (Keller, 1985; Khan, 2008). Distribusi Invers Weibull merupakan distribusi peluang waktu hidup yang dapat digunakan dalam reliabilitas ilmu pengetahuan bidang teknik. Distribusi invers weibull dapat digunakan untuk memodelkan waktu hidup suatu komponen. Sebagai contoh, waktu hidup piston. Waktu hidup piston terkadang dicatat sebanyak satu kali per hari, per minggu, atau per bulan, sebagai akibatnya waktu hidup piston dapat berupa countable set dengan model yang dapat digunakan adalah variabel acak diskrit. Jika model waktu hidup piston adalah variabel acak diskrit, maka dapat menggunakan bentuk diskrit dari distribusi invers weibull untuk distribusi model waktu hidup piston tersebut. Bentuk diskrit dari distribusi invers weibull disebut juga distribusi invers weibull diskrit. Selanjutnya, jika peneliti tertarik memodelkan waktu hidup per hari dari piston jenis 1 dan piston jenis 2 , maka dapat digunakan distribusi invers weibull diskrit bivariat.

Banyak peneliti yang telah melakukan kajian terhadap distribusi invers weibull. Distribusi invers weibull sendiri perkenalkan oleh Keller pada tahun 1985. Khan (2008) telah mengkaji mengenai analisis teori dari distribusi invers weibull. Distribusi invers weibull dapat dianalogikan ke dalam bentuk diskrit (Jazi, 2010). Distribusi invers weibull dapat dikonstruksi menjadi distribusi invers weibull bivariat (Kundu, 2017). Selain invers weibull, bentuk diskrit dari invers weibull juga dapat dikonstruksi menjadi distribusi invers weibull diskrit bivariat (Eliwa, 2018). Dalam penelitiannya, Eliwa menuliskan bentuk distribusi invers weibull diskrit bivariat, estimasi parameternya serta beberapa karakteristiknya, seperti median, koefisien dari korelasi median dan fungsi pembangkit peluang. Penelitian ini membahas mengenai konstruksi distribusi invers weibull diskrit bivariat serta beberapa karakteristiknya, seperti mixed moment, kovariansi, dan koefisien korelasi.

\section{METODE PENELITIAN}

\section{Distribusi Invers Weibul Diskrit Bivariat}

Pada bagian ini akan dibahas konstruksi distribusi invers weibull diskrit bivariat. Distribusi invers weibull diskrit dinotasikan sebagai berikut.

$$
W \approx \operatorname{DsIW}(w ; \theta, \alpha),
$$

Mempunyai fungsi distribusi kumulatif

$$
F_{W}(w)=\theta^{(w+1)^{-\alpha}},
$$

dengan $0<\theta<1$ dan $\alpha>0$. Misal, diketahui $\mathrm{W}_{1} \sim \operatorname{DsIW}\left(\mathrm{w}_{1} ; \theta_{1}, \alpha\right), \mathrm{W}_{2} \sim \operatorname{DsIW}\left(w_{2} ; \theta_{2}, \alpha\right)$, dan $W_{3}$ $\sim \operatorname{DsIW}\left(w_{3} ; \theta_{3}, \alpha\right)$ merupakan variabel acak yang saling independen. Definisikan $X_{l}=\max \left(W_{l}, W_{3}\right)$ dan $X_{2}=\max \left(W_{2}, W_{3}\right)$, maka fungsi distribusi kumulatif bersama untuk variabel acak $\mathrm{X}_{1}$ dan $\mathrm{X}_{2}$ dengan $x_{1}$ $=0,1,2, \ldots$ dan $x_{2}=0,1,2, \ldots$ adalah.

$$
\begin{aligned}
& F_{X_{1}, X_{2}}\left(x_{1}, x_{2}\right)=P\left(X_{1} \leq x_{1}, X_{2} \leq x_{2}\right)=P\left(\max \left(W_{1}, W_{3}\right) \leq x_{1}, \max \left(W_{2}, W_{3}\right) \leq\right. \\
& \left.x_{2}\right)=P\left(W_{1} \leq x_{1}, W_{2} \leq x_{2}, W_{3} \leq \min \left(x_{1}, x_{2}\right)=\right. \\
& F_{W_{1}}\left(x_{1}\right) F_{W_{2}}\left(x_{2}\right) F_{W_{3}}\left(\min \left(x_{1}, x_{2}\right)\right)= \\
& \left\{\begin{array}{c}
\left(\theta_{1} \theta_{3}\right)^{\left(x_{1}+1\right)^{-\alpha}} \theta_{2}\left(x_{2}+1\right)^{-\alpha}, 0<x_{1}<x_{2}<\infty \\
\theta_{1}^{\left(x_{1}+1\right)^{-\alpha}}\left(\theta_{2} \theta_{3}\right)^{\left(x_{2}+1\right)^{-\alpha}}, 0<x_{2}<x_{1}<\infty . \\
\left(\theta_{1} \theta_{2} \theta_{3}\right)^{(x+1)^{-\alpha}}, 0<x_{1}=x_{2}=x<\infty
\end{array}\right.
\end{aligned}
$$

Berdasarkan fungsi distribusi kumulatif bersama $F_{X_{1}, X_{n}}\left(x_{1}, x_{2}\right)$, dapat dicari fungsi distribusi kumulatif marginal $X_{I}$ 


$$
\begin{aligned}
& F_{X_{1}}\left(x_{1}\right)=F_{X_{1}, x_{2}}\left(x_{1}, \infty\right)=F_{W_{1}}\left(x_{1}\right) F_{W_{1}}(\infty) F_{W_{g}}\left(\min \left(x_{1}, \infty\right)\right)= \\
& F_{W_{1}}\left(x_{1}\right) F_{W_{R}}\left(x_{1}\right)=\left(\theta_{1} \theta_{3}\right)^{\left(x_{1}+1\right)^{-\alpha}},
\end{aligned}
$$

dan fungsi distribusi kumulatif marginal $X_{2}$

$$
\begin{aligned}
& F_{X_{2}}\left(x_{2}\right)=F_{X_{1}, X_{2}}\left(\infty, x_{2}\right)=F_{W_{1}}(\infty) F_{W_{1}}\left(x_{2}\right) F_{W_{a}}\left(\min \left(\infty, x_{2}\right)\right)= \\
& F_{W_{n}}\left(x_{2}\right) F_{W_{R}}\left(x_{2}\right)=\left(\theta_{2} \theta_{3}\right)^{\left(x_{2}+1\right)^{-\alpha}} .
\end{aligned}
$$

Fungsi kepadatan peluang bersama dari distribusi invers weibull diskrit bivariat yang didapat adalah

$$
f_{X_{1}, X_{2}}\left(x_{1}, x_{2}\right)=\left\{\begin{array}{c}
f_{1}\left(x_{1}, x_{2}\right), x_{1}<x_{2} \\
f_{2}\left(x_{1}, x_{2}\right), x_{2}<x_{1} \\
f_{3}(x, x), x_{1}=x_{2}=x
\end{array},\right.
$$

dengan

$$
\begin{aligned}
& f_{1}\left(x_{1}, x_{2}\right)=\left(\left(\theta_{1} \theta_{3}\right)^{\left(x_{1}+1\right)^{-\alpha}}-\left(\theta_{1} \theta_{3}\right)^{x_{1}-\alpha}\right)\left(\theta_{2}^{\left(x_{2}+1\right)^{-\alpha}}-\theta_{2}^{x_{2}-\alpha}\right), \\
& f_{2}\left(x_{1}, x_{2}\right)=\left(\theta_{1}^{\left(x_{1}+1\right)^{-\alpha}}-\theta_{1}^{x_{1}^{-\alpha}}\right)\left(\left(\theta_{2} \theta_{3}\right)^{\left(x_{2}+1\right)^{-\alpha}}-\left(\theta_{2} \theta_{3}\right)^{x_{2}-\alpha}\right),
\end{aligned}
$$

dan

$$
f_{3}\left(x_{1}, x_{2}\right)=\theta_{2}^{(x+1)^{-\alpha}}\left(\left(\theta_{1} \theta_{3}\right)^{(x+1)^{-\alpha}}-\left(\theta_{1} \theta_{3}\right)^{x^{-\alpha}}\right)-\left(\theta_{2} \theta_{3}\right)^{x^{-\alpha}}\left(\theta_{1}^{(x+1)^{-\alpha}}-\theta_{1}^{x^{-\alpha}}\right)
$$

\section{HASIL DAN PEMBAHASAN}

\section{Karakteristik Distribusi Invers Weibull Diskrit Bivariat}

Pada bagian ini akan dibahas mixed moment, kovariansi, dan koefisien korelasi dari distribusi invers weibull diskrit bivariat. Berdasarkan fungsi kepadatan peluang bersama, didapat fungsi pembangkit momen bersama dari distribusi invers weibull diskrit bivariat.

$$
\begin{aligned}
& M_{X_{1} x_{2}}\left(t_{1}, t_{2}\right)=\sum_{i=0}^{\infty}\left[e ^ { t _ { 1 } i } e ^ { t _ { 2 } i } \left(\theta_{2}^{(i+1)^{-\alpha}}\left(\left(\theta_{1} \theta_{3}\right)^{(i+1)^{-\alpha}}-\left(\theta_{1} \theta_{3}\right)^{i^{-\alpha}}\right)-\right.\right. \\
& \left.\left.\left(\theta_{2} \theta_{3}\right)^{i^{-\alpha}}\left(\theta_{1}^{(i+1)^{-\alpha}}-\theta_{1}^{i^{-\alpha}}\right)\right)\right]+\sum_{j=1}^{\infty} \sum_{i=0}^{j-1}\left[e ^ { t _ { 1 } i } e ^ { t _ { 2 } j } \left(\left(\theta_{1} \theta_{3}\right)^{(i+1)^{-\alpha}}-\right.\right. \\
& \left.\left.\left.\left(\theta_{1} \theta_{3}\right)^{i^{-\alpha}}\right)\left(\theta_{2}^{(j+1)^{-\alpha}}-\theta_{2}{ }^{j^{-\alpha}}\right)\right)\right]+\sum_{j=0}^{\infty} \sum_{i=J+1}^{\infty}\left[e ^ { t _ { 1 } i } e ^ { t _ { 2 } j } \left(\left(\theta_{1}^{(i+1)^{-\alpha}}-\right.\right.\right. \\
& \left.\left.\left.\theta_{1}^{i^{-\alpha}}\right)\left(\left(\theta_{2} \theta_{2}\right)^{(j+1)^{-\alpha}}-\left(\theta_{2} \theta_{2}\right)^{j^{-\alpha}}\right)\right)\right]
\end{aligned}
$$

Selanjutnya, dari fungsi pembangkit momen bersama distribusi invers weibull diskrit bivariat didapatkan.

$$
\begin{aligned}
& E\left(X_{1} X_{2}\right)=\sum_{i=0}^{\infty}\left[i ^ { 2 } \left(\theta_{2}^{(i+1)^{-\alpha}}\left(\left(\theta_{1} \theta_{3}\right)^{(i+1)^{-\alpha}}-\left(\theta_{1} \theta_{3}\right)^{i^{-\alpha}}\right)-\right.\right. \\
& \left.\left.\left(\theta_{2} \theta_{3}\right)^{i^{-\alpha}}\left(\theta_{1}^{(i+1)^{-\alpha}}-\theta_{1}^{i^{-\alpha}}\right)\right)\right]+\sum_{j=1}^{\infty} \sum_{i=0}^{j-1}\left[i j \left(\left(\theta_{1} \theta_{3}\right)^{(i+1)^{-\alpha}}-\right.\right. \\
& \left.\left.\left.\left(\theta_{1} \theta_{3}\right)^{i^{-\alpha}}\right)\left(\theta_{2}{ }^{(j+1)^{-\alpha}}-\theta_{2}{ }^{-\alpha}\right)\right)\right]+\sum_{j=0}^{\infty} \sum_{i=J+1}^{\infty}\left[i j \left(\left(\theta_{1}{ }^{(i+1)^{-\alpha}}-\right.\right.\right. \\
& \left.\left.\left.\theta_{1}^{i^{-\alpha}}\right)\left(\left(\theta_{2} \theta_{3}\right)^{(j+1)^{-\alpha}}-\left(\theta_{2} \theta_{3}\right)^{j^{-\alpha}}\right)\right)\right]
\end{aligned}
$$


Lebih umum, untuk setiap bilangan bulat positif $m$ dan $n$ didapat momen dari dua variabel acak (mixed moment).

$$
\begin{aligned}
& E\left(X_{1}{ }^{m} X_{2}{ }^{n}\right)=\sum_{i=0}^{\infty}\left[i ^ { m + n } \left(\theta_{2}{ }^{(i+1)^{-\alpha}}\left(\left(\theta_{1} \theta_{3}\right)^{(i+1)^{-\alpha}}-\left(\theta_{1} \theta_{3}\right)^{i^{-\alpha}}\right)-\right.\right. \\
& \left.\left.\left(\theta_{2} \theta_{3}\right)^{i^{-\alpha}}\left(\theta_{1}{ }^{(i+1)^{-\alpha}}-\theta_{1}{ }^{-\alpha}\right)\right)\right]+\sum_{j=1}^{\infty} \sum_{i=0}^{j-1}\left[1 ^ { m } j ^ { n } \left(\left(\theta_{1} \theta_{3}\right)^{(i+1)^{-\alpha}}-\right.\right. \\
& \left.\left.\left.\left(\theta_{1} \theta_{3}\right)^{i^{-\alpha}}\right)\left(\theta_{2}{ }^{(j+1)^{-\alpha}}-\theta_{2}{ }^{-\alpha}\right)\right)\right]+\sum_{j=0}^{\infty} \sum_{i=1+1}^{\infty}\left[i ^ { m } j ^ { n } \left(\left(\theta_{1}{ }^{(i+1)^{-\alpha}}-\right.\right.\right. \\
& \left.\left.\left.\theta_{1}{ }^{i^{-\alpha}}\right)\left(\left(\theta_{2} \theta_{3}\right)^{(j+1)^{-\alpha}}-\left(\theta_{2} \theta_{3}\right)^{j^{-\alpha}}\right)\right)\right]
\end{aligned}
$$

dari mixed moment didapat, untuk $\mathrm{m}=1$ dan $\mathrm{n}=0$,

$$
\begin{aligned}
& E\left(X_{1}\right)=\sum_{i=0}^{\infty}\left[i \left(\theta_{2}^{(i+1)^{-\alpha}}\left(\left(\theta_{1} \theta_{3}\right)^{(i+1)^{-\alpha}}-\left(\theta_{1} \theta_{3}\right)^{i^{-\alpha}}\right)-\left(\theta_{2} \theta_{3}\right)^{i^{-\alpha}}\left(\theta_{1}^{(i+1)^{-\alpha}}-\right.\right.\right. \\
& \left.\left.\left.\left.\theta_{1}^{i^{-\alpha}}\right)\right)\right]+\sum_{j=1}^{\infty} \sum_{i=0}^{j-1}\left[i\left(\left(\theta_{1} \theta_{3}\right)^{(i+1)^{-\alpha}}-\left(\theta_{1} \theta_{3}\right)^{i^{-\alpha}}\right)\left(\theta_{2}{ }^{(j+1)^{-\alpha}}-\theta_{2}{ }^{-\alpha}\right)\right)\right]+ \\
& \sum_{j=0}^{\infty} \sum_{i=J+1}^{\infty}\left[i\left(\left(\theta_{1}^{(i+1)^{-\alpha}}-\theta_{1}^{i^{-\alpha}}\right)\left(\left(\theta_{2} \theta_{3}\right)^{(j+1)^{-\alpha}}-\left(\theta_{2} \theta_{3}\right)^{j^{-\alpha}}\right)\right)\right]
\end{aligned}
$$

untuk $\mathrm{m}=0$ dan $\mathrm{n}=1$,

$$
\begin{aligned}
& E\left(X_{2}\right)=\sum_{i=0}^{\infty}\left[i \left(\theta_{2}{ }^{(i+1)^{-\alpha}}\left(\left(\theta_{1} \theta_{3}\right)^{(i+1)^{-\alpha}}-\left(\theta_{1} \theta_{3}\right)^{i^{-\alpha}}\right)-\left(\theta_{2} \theta_{3}\right)^{i^{-\alpha}}\left(\theta_{1}^{(i+1)^{-\alpha}}-\right.\right.\right. \\
& \left.\left.\left.\left.\theta_{1}^{i^{-\alpha}}\right)\right)\right]+\sum_{j=1}^{\infty} \sum_{i=0}^{j-1}\left[j\left(\left(\theta_{1} \theta_{3}\right)^{(i+1)^{-\alpha}}-\left(\theta_{1} \theta_{3}\right)^{i^{-\alpha}}\right)\left(\theta_{2}{ }^{(j+1)^{-\alpha}}-\theta_{2}{ }^{j^{-\alpha}}\right)\right)\right]+ \\
& \sum_{j=0}^{\infty} \sum_{i=1+1}^{\infty}\left[j\left(\left(\theta_{1}{ }^{(i+1)^{-\alpha}}-\theta_{1}{ }^{i^{-\alpha}}\right)\left(\left(\theta_{2} \theta_{3}\right)^{(j+1)^{-\alpha}}-\left(\theta_{2} \theta_{3}\right)^{j^{-\alpha}}\right)\right)\right]
\end{aligned}
$$

Sebagai akibatnya didapat kovariansi dari variabel acak $X_{1}$ dan $X_{2}$

$$
\sigma_{X_{1} X_{\mathrm{m}}}=E\left(X_{1} X_{2}\right)-E\left(X_{1}\right) E\left(X_{2}\right),
$$

Dengan $E\left(X_{I} X_{2}\right)$ pada persamaan (11), $\mathrm{E}\left(X_{1}\right)$ pada persamaan (12), dan $\mathrm{E}\left(X_{2}\right)$ pada persamaan (13). Selanjutnya, dapat dicari variansi $X_{l}$ dengan menggunakan persamaan (12) dan mixed moment saat $\mathrm{m}$ $=2, \mathrm{n}=0$. Serta dapat dicari variansi $X_{2}$ dengan menggunakan persamaan (3) dan mixed moment saat $\mathrm{m}=0, \mathrm{n}=2$. Sebagai akibatnya, dapat dicari koefisien korelasi dari variabel acak $X_{1}$ dan $X_{2}$.

Contoh Misal $\theta_{1}=0.99, \theta_{2}=0.235, \theta_{3}=0.6$, dan $\alpha=4$. Maka untuk $\mathrm{z}=100,300,500,800,1000$, 2000 dengan menggunakan program Octave didapatkan hasil sebagai berikut.

TABEL 1. Hasil perhitungan menggunakan program Octave

\begin{tabular}{cccccc}
\hline $\mathbf{z}$ & $\mathbf{E}\left(\boldsymbol{X}_{\boldsymbol{I}} \boldsymbol{X}_{\boldsymbol{2}}\right)$ & $\mathbf{E}\left(\boldsymbol{X}_{\boldsymbol{I}}\right)$ & $\mathbf{E}\left(\boldsymbol{X}_{2}\right)$ & $\boldsymbol{E}\left(\boldsymbol{X}_{1}{ }^{2}\right)$ & $\boldsymbol{E}\left(\boldsymbol{X}_{\boldsymbol{2}}{ }^{2}\right)$ \\
\hline 100 & 0.61273 & 0.44681 & 0.48999 & 0.56995 & 0.74228 \\
300 & 0.61282 & 0.44681 & 0.48999 & 0.57004 & 0.74247 \\
500 & 0.61283 & 0.44681 & 0.48999 & 0.57004 & 0.74249 \\
800 & 0.61283 & 0.44681 & 0.48999 & 0.57004 & 0.74249 \\
1000 & 0.61283 & 0.44681 & 0.48999 & 0.57004 & 0.74249 \\
2000 & 0.61283 & 0.44681 & 0.48999 & 0.57004 & 0.74250 \\
\hline
\end{tabular}

Sebagai akibatnya, untuk $\mathrm{z}=2000$ didapat kovariansi

$\sigma_{X_{1} X_{2}}=E\left(X_{1} X_{2}\right)-E\left(X_{1}\right) E\left(X_{2}\right)=0.61283-(0.44681 \cdot 0.48999)=0.39390$

dan koefisien korelasi

$$
\rho=\frac{\sigma_{X_{1} X_{2}}}{\sqrt{\sigma_{X_{1}}{ }^{2}} \sqrt{\sigma_{X_{2}}{ }^{2}}}=\frac{0.39390}{\sqrt{0.37041} \sqrt{0.50241}}=0.91309
$$




\section{KESIMPULAN}

Penelitian ini telah dibahas kembali secara lebih detail mengenai konstruksi dan karakteristik distribusi invers weibull diskrit bivariat. Karakteristik yang dibahas adalah mixed moment, kovariansi, dan koefisien korelasi. Perhitungan numerik dengan menggunakan program Octave diberikan pada penelitian ini untuk menunjukkan kinerja langsung dari mixed moment.

\section{UCAPAN TERIMA KASIH}

Terima kasih kepada Bapak Prof. Dr. Suyono, M.Si. dan Ibu Ir. Fariani Hermin Indiyah, M.T. yang sudah menyediakan waktu, tenaga, pikiran untuk membimbing penulis serta mengarahkan penulis, sehingga penelitian ini berhasil selesai dengan baik.

\section{REFERENSI}

Bain, Lee J., Engelhardt, Max. (1991) Introduction to Probability and Mathematical Statistics 2nd Edition. USA: Duxbury.

Eliwa, M. S, El-Morshedy, M. (2018) 'Bivariate Discrete Inverse Weibull Distribution', arXiv preprint arXiv:1808.07748

Hogg, Robert V., Craig, Allen T. (1978) Introduction to Mathematical Statistics 4th Edition. USA: Macmillan Publishing Co.

Jazi, M.A., Lai, C.D. and Alamatsaz, M.H. (2010) 'A discrete inverse Weibull distribution and estimation of its parameters', Statistical Methodology, 7(2), pp.121-132.

Johnson, Norman L., Kemp, Adrienne W., Kotz, Samuel. (2005) Univariate Discrete Distributions. New Jersey: John Wiley \& Sons.

Keller, A.Z., Goblin, M.T. and Farnworth, N.R. (1985) 'Reliability analysis of commercial vehicle engines', Reliability Engineering, 10(1), pp.15-25.

Khan, M.S., Pasha, G.R. and Pasha, A.H. (2008) 'Theoretical analysis of inverse Weibull distribution', WSEAS Transactions on Mathematics, 7(2), pp.30-38.

Kundu, D. and Gupta, A.K. (2017) 'On bivariate inverse Weibull distribution'. Brazilian Journal of Probability and Statistics, 31(2), pp.275-302. 